\title{
Autophagy in diabetic nephropathy
}

\section{Yan Ding and Mary E Choi}

Division of Nephrology and Hypertension, Joan and Sanford I. Weill Department of Medicine, Weill Cornell Medical College, 525 East 68th Street, Box 3, New York, New York 10065, USA
Correspondence should be addressed to $\mathrm{MEChoi}$

Email

mechoi@med.cornell.edu

\begin{abstract}
Diabetic nephropathy (DN) is the most common cause of end-stage kidney disease worldwide, and is associated with increased morbidity and mortality in patients with both type 1 and type 2 diabetes. Increasing prevalence of diabetes has made the need for effective treatment of DN critical and thereby identifying new therapeutic targets to improve clinical management. Autophagy is a highly conserved 'self-eating' pathway by which cells degrade and recycle macromolecules and organelles. Autophagy serves as an essential mechanism to maintain homeostasis of glomeruli and tubules, and plays important roles in human health and diseases. Impairment of autophagy is implicated in the pathogenesis of DN. Emerging body of evidence suggests that targeting the autophagic pathway to activate and restore autophagy activity may be renoprotective. In this review, we examine current advances in our understanding of the roles of autophagy in diabetic kidney injury, focusing on studies in renal cells in culture, human kidney tissues, and experimental animal models of diabetes. We discuss the major nutrient-sensing signal pathways and diabetes-induced altered intracellular metabolism and cellular events, including accumulation of advanced glycation end-products, increased oxidative stress, endoplasmic reticulum stress, hypoxia, and activation of the renin-angiotensin system, which modulate autophagic activity and contribute to the development of DN. We also highlight recent studies of autophagy and transforming growth factor- $\beta$ in renal fibrosis, the final common response to injury that ultimately leads to end-stage kidney failure in both type 1 and type 2 diabetes. These findings suggest the possibility that autophagy can be a therapeutic target against DN.
\end{abstract}

\author{
Key Words \\ - diabetes mellitus \\ - macroautophagy \\ - autophagy \\ - kidney \\ - nephropathy
}

Journal of Endocrinology (2015) 224, R15-R30

\section{Introduction}

The rapidly increasing prevalence of diabetes mellitus has become a major global health issue. This has been, in large part, driven by the escalating epidemic of metabolic syndrome and obesity (Hu 2011). It is projected that the number of people with diabetes worldwide will increase from 382 million in 2013 to 592 million by 2035, according to the International Diabetes Federation (Shi $\&$ Hu 2014). Diabetic nephropathy (DN) is one of the most devastating complications of diabetes and the leading single cause of end-stage kidney disease. It accounts for a significant increase in morbidity and mortality in patients with diabetes, underscoring the importance of therapeutic interventions directed at preventing the development and progression of diabetic kidney disease.

Clinical features of DN include elevated urinary albumin excretion, impaired glomerular filtration rate (GFR), and progressive decline in kidney function that ultimately lead to end-stage kidney failure. Hyperglycemiamediated alterations of intracellular metabolism, including the accumulation of advanced glycation end-products (AGEs), activation of protein kinase C (PKC), and oxidative stress are the major contributing factors to the pathogenesis of DN (Calcutt et al. 2009, Giacco \& Brownlee 2010). Increased flux of glucose through the polyol

Published by Bioscientifica Ltd. 
pathway is a major cause of oxidative stress. Chronic hyperglycemia also activates the diacylglycerol-PKC pathway, which contributes to the regulation of vascular permeability, vasoconstriction, extracellular matrix (ECM) synthesis and turnover, cell growth, angiogenesis, cytokine activation, and leukocyte adhesion (Noh \& King 2007). Moreover, hemodynamic changes resulting in systemic and glomerular hypertension and the role of the renin-angiotensin system (RAS) have been also implicated in the pathogenesis of DN in both type 1 and type 2 diabetes (Brenner et al. 2001, Lewis et al. 2001, Ruggenenti et al. 2010, Har et al. 2013). Current therapies for $\mathrm{DN}$ are aimed at controlling blood glucose levels and blood pressure, and in particular, inhibition of the RAS to reduce or abrogate the development of albuminuria and progression of DN (Brenner et al. 2001, Ruggenenti et al. 2010). However, the incidence of diabetic kidney disease continues to increase and many patients with DN experience progressive kidney function decline resulting in end-stage kidney disease. Hence, there is a critical need to further our understanding of the pathogenesis of DN in order to identify new therapeutic targets and improve clinical management.

Autophagy is an evolutionarily conserved homeostatic cellular process that has garnered widespread interest as an important pathway in many biological functions. It plays key roles in normal and disease states, including immunity, inflammation, adaptation to stress, development and aging, metabolic and neurodegenerative disorders, and cancer (Choi et al. 2013). Autophagy is a tightly regulated process in which cellular protein aggregates and damaged organelles are degraded via the lysosomal pathway. Emerging body of evidence also implicates impaired autophagic activity in the pathogenesis of diabetic kidney disease. In this review, we examine the current advances in our understanding of the role of autophagy in DN. Targeting the autophagic pathway is an intriguing therapeutic strategy for DN.

\section{Autophagy}

Autophagy (derived from the Greek word meaning 'self-eating') represents a fundamental cellular process that delivers intracellular constituents to lysosomes for degradation to maintain homeostasis and cell integrity. The term 'autophagy' was first used in 1963 by Christian de Duve, who received the Nobel Prize for his work on lysosomes (Ravikumar et al. 2010). Early studies demonstrated autophagy as a stress-adaptive response induced during nutrient starvation to provide nutrients and energy to cells through recycling of endogenous materials (Mortimore \& Pösö 1987). During the last decade, studies defining the basic cellular mechanisms of autophagy have provided evidence for its roles in human health and disease (Choi et al. 2013).

Among the three major types of autophagy that have been described, namely macroautophagy, microautophagy, and chaperone-mediated autophagy (Fig. 1), macroautophagy, hereafter referred to as autophagy, is the most intensively investigated and the focus of this review. The process of autophagy initiates with the formation of the phagophore, also known as the isolation membrane, around cytoplasmic components that will be sequestered by doublemembraned autophagosome forming at the endoplasmic reticulum (ER)-mitochondria contact site in mammalian cells (Hamasaki et al. 2013). The autophagosome subsequently fuses with the lysosome to form autolysosome, and the enclosed contents are degraded and recycled (Fig. 1). In microautophagy, the cytosolic contents are engulfed by direct invagination of the lysosomal membranes forming single-membraned vesicles and get rapidly degraded (Mijaljica et al. 2011). Chaperone-mediated autophagy involves selective mechanism for the degradation of cytosolic proteins containing a pentapeptide motif with a consensus sequence such as KFERQ that is recognized by a chaperone complex, the heat shock-cognate chaperone of $70 \mathrm{kDa}$ (hsc70), and delivered to lysosomes (Arias \& Cuervo 2010). Subsequent binding of substrate proteins to the lysosome-associated membrane protein type-2A (LAMP2A) facilitates internalization through a membrane translocation complex and degradation (Fig. 1).

Autophagy is a well-coordinated multi-step process regulated by autophagy-related gene (Atg) products originally identified in yeast. In mammals, the initiation step of autophagosome formation involves the UNC51like kinase 1/2 (ULK1/2) complex, comprising ULK1/ 2-ATG13-FIP200, and requires the activity of the class III phosphatidylinositol 3-kinase (PI3K), VPS34 (Ravikumar et al. 2010). The activity of VPS34 is enhanced by its interaction with Beclin 1, and the VPS34-ATG14L complex facilitates vesicle nucleation and phagophore formation (Zhong et al. 2009, He \& Levine 2010). Beclin 1 also interacts with other binding proteins such as ambra-1, U.v.-radiation resistance-associated gene (UVRAG), and BIF1, and disruption of their interaction with Beclin 1 affects autophagosome formation. Interestingly, the binding of the anti-apoptotic proteins $\mathrm{BCl} 2$ or $\mathrm{BCLX}_{\mathrm{L}}$ to Beclin 1 inhibits autophagy. Two ubiquitin-like conjugation systems, namely the ATG12-ATG5.ATG16L1 tetrameric complex and the microtubule-associated protein 1 light chain 3 (LC3)/ATG8, are required for autophagosomal

Published by Bioscientifica Ltd 


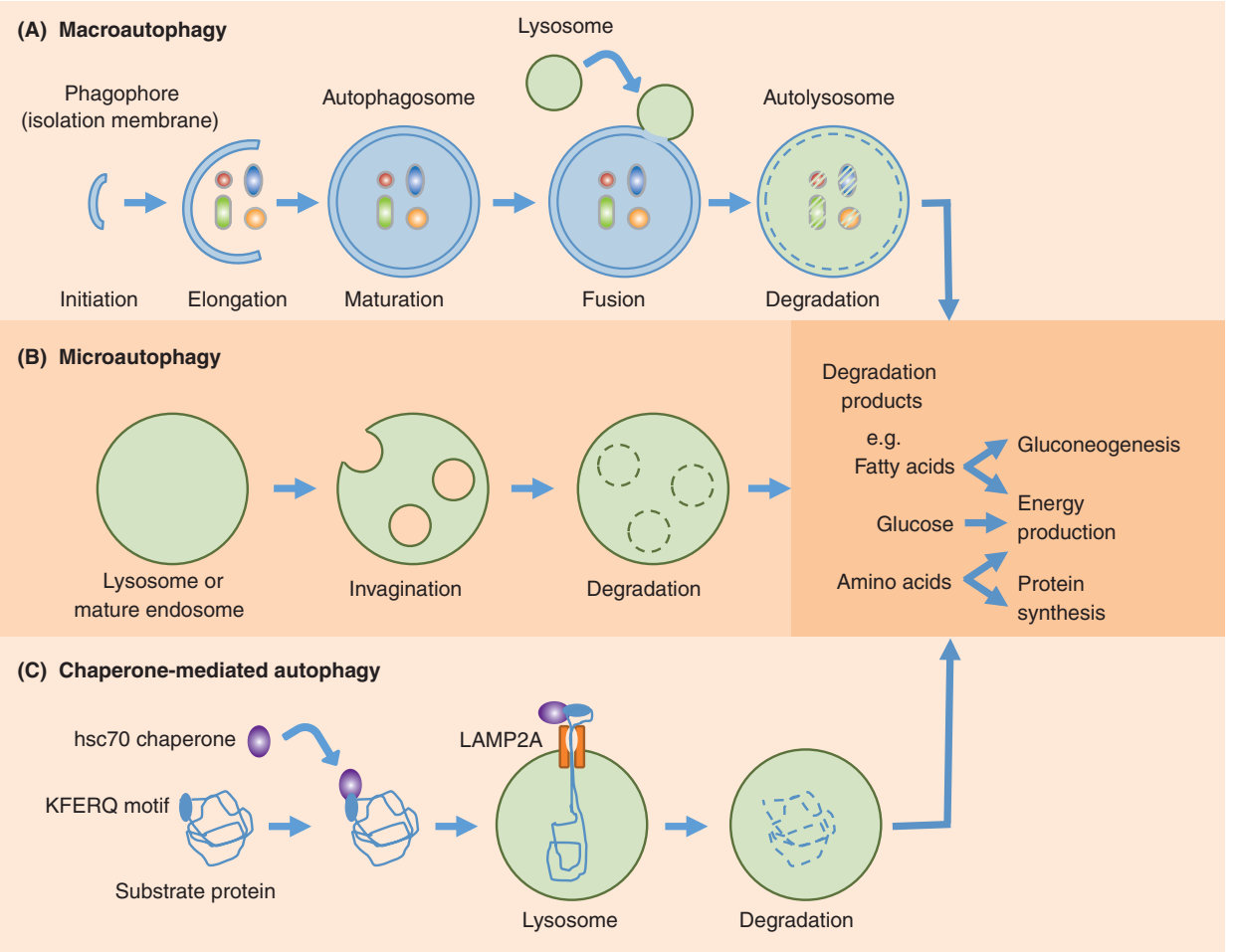

\section{Figure 1}

Schematic diagram of the three major types of autophagy. (A) Macroautophagy (generally referred as autophagy) initiates with the formation of the phagophore (isolation membrane) around cytosolic components and sequestration by double-membraned vesicles called autophagosomes. Fusion with lysosomes form autolysosomes and the sequestered components are degraded and recycled. (B) In microautophagy, the lysosomes

elongation (Ravikumar et al. 2010). The conversion of a cytosolic truncated form (LC3-I) to its autophagosomal membrane-associated, phosphatidylethanolamine-conjugated form (LC3-II), indicates autophagosome formation. The maturation step involves UVRAG interaction with the class C VPS proteins and subsequent activation of RAB7, thereby promoting fusion of autophagosomes with lysosomes. On the other hand, rubicon is a recently identified Beclin 1 interacting protein which suppresses autophagosome maturation via a distinct complex formation with Beclin 1 containing VPS34, VPS15, and UVRAG (Zhong et al. 2009, Ravikumar et al. 2010). Thus, each complex contributes to a different function during autophagy. Disruption of any of these complexes or core gene products results in impaired autophagy, indicating that a sequential reaction is indispensable for the autophagy process.

\section{Impaired autophagy in the diabetic kidney}

Dysregulated autophagy has been suggested to play important pathogenic roles in a variety of disease processes. directly engulf cytosolic contents for degradation through invaginations of the lysosomal membrane and internalization of single-membraned vesicles. (C) Chaperone-mediated autophagy selectively degrades proteins containing KFERQ motif that are recognized by the heat shock cognate protein of $70 \mathrm{kDa}$ (hsc70) chaperone, and transported into lysosomes via cooperation with lysosome-associated membrane protein-2A (LAMP2A).

Accumulating body of evidence implicates that autophagy regulates many critical aspects of normal and disease conditions in the kidney (Wang \& Choi 2014). Studies indicate that diabetic kidneys are deficient in autophagic activity. Cellular autophagy was inhibited in the kidney cortex tubules of streptozotocin (STZ)-induced earlydiabetic rats, with associated renal hypertrophy, and that insulin replacement by insulin treatment or islet transplantation reversed the inhibition of autophagy (Barbosa et al. 1992, Han et al. 1997). Impaired autophagy evidenced by renal accumulation of p62/Sequestosome 1 (SQSTM1), a substrate of autophagy-lysosomal degradation pathway, was also shown in STZ-induced diabetic mice (Vallon et al. 2013) and Wistar fatty rats (Kitada et al. 2011a), which are models of type 1 and type 2 diabetes respectively. In addition, increase in chaperone-mediated autophagy substrate proteins in the kidney cortex and a decrease in proteins that regulate this pathway, such as LAMP-2A, were also seen in STZ-induced early-diabetic rats with renal hypertrophy (Sooparb et al. 2004). Taken together, these pre-clinical studies indicate an impairment of autophagy at 
the early stage of experimental diabetic kidney disease. Moreover, evidence of impaired autophagy has also been observed in kidney biopsy samples from patients with type 2 diabetes exhibiting accumulation of p62/SQSTM1 protein in proximal tubular cells, suggesting that deficiency in autophagy also occurs in human type 2 diabetes (Yamahara et al. 2013).

\section{mTOR and autophagy in the diabetic kidney}

The mechanistic target of rapamycin (mTOR) is the classical nutrient-sensing pathway regulating autophagic activity through its association with two distinct protein complexes, mTOR complex 1 (mTORC1) and mTORC2. In general, mTORC1 is a negative regulator of autophagy by inhibiting the activity of the ULK1 complex through direct phosphorylation. Nutrient starvation induces autophagy primarily through the inhibition of mTORC1 (Zoncu et al. 2011). Autophagy induced during starvation, growth factor deprivation, hypoxia, and ER stress can prevent cell death and is thought to represent survival mechanism. Recent studies have suggested that the pathogenesis of $\mathrm{DN}$ is associated with impaired autophagic activity via activation of the mTOR pathway (Fig. 2).

Enhanced mTORC1 activity is seen in human and experimental type 1 and type 2 DN (Lloberas et al. 2006, Mori et al. 2009, Gödel et al. 2011) Moreover, podocytespecific activation of mTORC1 results in many features of DN, such as mesangial expansion, glomerular basement membrane (GBM) thickening, podocyte loss, and proteinuria in nondiabetic mice (Inoki et al. 2011). Treatment with rapamycin, an inhibitor of mTORC1, suppressed the development of DN in STZ-induced diabetic rats and $d b / d b$ mice, models of type 1 and type 2 diabetes

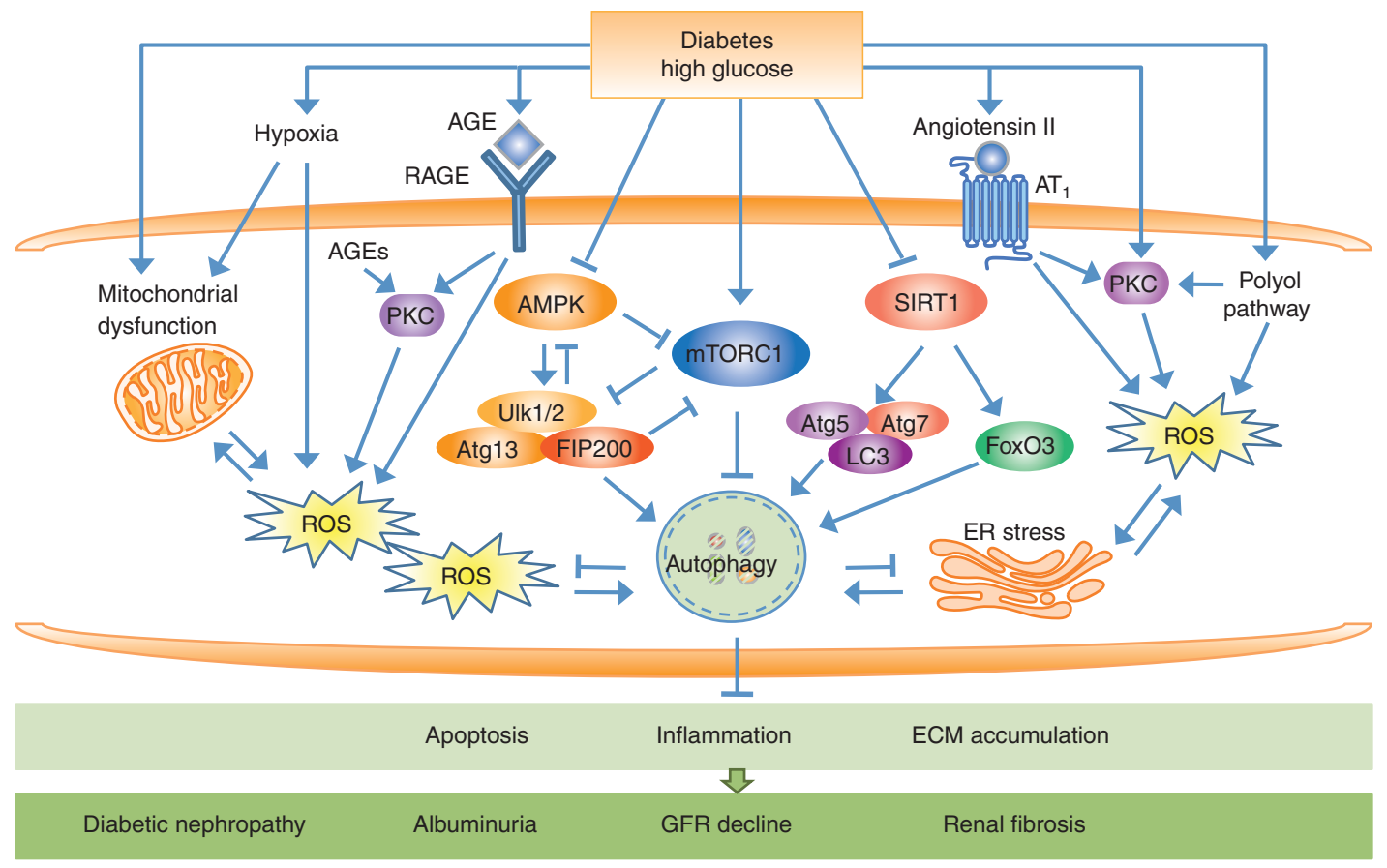

Figure 2

An overview of the regulation of autophagy by extracellular and intracellular stresses in the pathogenesis of diabetic nephropathy (DN). Three major nutrient-sensing signal pathways modulate autophagy activity under diabetic conditions through activation of mTORC1 and inhibition of AMPK and SIRT1 to negatively regulate autophagy activity. AMPK and mTORC1 oppositely regulate the ULK1/2-ATG13-FIP200 complex. AMPK directly activates ULK $1 / 2$ to induce autophagy. SIRT1 interacts with the essential components of the autophagy machinery, such as ATG5, ATG7, and LC3, and the transcription factor FOXO3 to induce autophagy. Diabetes also induces alterations in intracellular metabolism, such as accumulation of intracellular advanced glycation end-products (AGEs) and extracellular AGEs that act via their interaction with receptor for AGEs (RAGE). Other cellular events include increased reactive oxygen species (ROS), endoplasmic reticulum (ER) stress, enhanced protein kinase C (PKC) activity and increased flux through polyol pathways, hypoxia, and activation of the rennin-angiotensin system (RAS), which modulate autophagic activity and contribute to the development of DN. Impairment of autophagy activity lead to cellular injury responses including apoptosis, inflammation, and ECM accumulation, resulting in progression of DN with the development of albuminuria, decline in GFR, and renal fibrosis. mTORC1, mechanistic target of rapamycin complex 1; AMPK, AMP-activated protein kinase (AMPK); SIRT1, silent information regulator T1; ULK1/2, Unc-51-like kinase 1/2; Atg, autophagy-related gene; LC3, microtubule-associated protein 1 light chain 3; FOXO3, forkhead box O3; ECM, extracellular matrix; GFR, glomerular filtration rate.

Published by Bioscientifica Ltd. 
respectively. Blockade of the mTOR pathway reduced glomerular $\alpha$-smooth muscle actin expression, mesangial matrix accumulation, and renal hypertrophy in STZinduced diabetes (Lloberas et al. 2006, Sakaguchi et al. 2006). Renal mRNA expression of proliferating cell nuclear antigen, transforming growth factor beta 1 (TGF $\beta 1$ ), vascular endothelial growth factor, and monocyte chemoattractant protein-1 was also reduced (Yang et al. 2007, Wittmann et al. 2009). Similarly, mTOR inhibition also ameliorated diabetic changes such as renal hypertrophy in $d b / d b$ mice (Sataranatarajan et al. 2007, Mori et al. 2009). These findings suggest that activation of the mTOR pathway has an important pathogenic role in DN.

\section{AMPK and autophagy in the diabetic kidney}

The AMP-activated protein kinase (AMPK) is a nutrientsensing kinase activated under energy-depleted conditions and is, in contrast to the mTOR pathway, a potent positive regulator of autophagy. AMPK is activated upon phosphorylation of a conserved threonine residue (T172) in the activation loop of the catalytic $\alpha$-subunit by several upstream kinases, including liver kinase B1 (LKB1), calcium/calmodulin-dependent kinase kinase beta (CaMKK $\beta$ ), and TGF $\beta$-activated kinase 1 (TAK1) (Alers et al. 2012). Both CaMKK $\beta$ - and TAK1-mediated activation of AMPK have been implicated in AMPK-mediated autophagy induction, triggered by increased intracellular calcium concentrations and tumor necrosis factor-related apoptosis-inducing ligand respectively. In addition, AMPK can also cross-talk with mTORC1 signaling to inhibit mTORC1 activity either via the the tuberous sclerosis complex (TSC)1/2-RHEB pathway or through phosphorylation of its regulatory-associated proteins such as Raptor (Lee et al. 2010, Alers et al. 2012). AMPK and mTORC1 oppositely regulate the ULK1/2-ATG13-FIP200 complex. Recent studies have shown that AMPK can bind, phosphorylate, and directly activate ULK1/2 to induce autophagy (Lee et al. 2010, Kim et al. 2011). This interaction is counteracted by mTORC1. ULK1 has also been shown to phosphorylate and inhibit both of its upstream regulators AMPK and mTORC1 to further fine-tune the autophagic response. Thus, a balance between the AMPK and mTOR pathways can directly regulate the activity of ULK1 to control autophagy induction (Fig. 2).

Findings in both type 1 and type 2 diabetic animal models provide evidence that AMPK phosphorylation and activity were suppressed in the glomeruli and tubules (Lee et al. 2007, Ding et al. 2010a, Kitada et al. 2011b). Furthermore, restoration of AMPK activity by the use of agents that are known activators of AMPK attenuated diabetic kidney injury. In STZ-induced diabetic rats, metformin and 5-aminoimidazole-4-carboxamide$1 \beta$-riboside (AICAR) increased renal AMPK phosphorylation, reversed mTOR activation, and inhibited renal hypertrophy (Lee et al. 2007). Metformin treatment also improves hyperglycemia via mechanisms that include the activation of AMPK (Sokolovska et al. 2010). Treatment with resveratrol, another AMPK activator, reversed the inhibition of AMPK in the STZ-induced diabetic kidney and reduced albuminuria, ameliorated hyperglycemia and renal dysfunction, and attenuated renal hypertrophy (Ding et al. 2010a, Chang et al. 2011). Resveratrol also significantly reduced urinary albumin excretion and attenuated renal pathological changes in $d b / d b$ mice (Kitada et al. 2011b). These studies suggest that inactivation of AMPK inhibits autophagy and contributes to the pathogenesis of DN. Thus, AMPK activation may be a target for restoring autophagy activity in diabetic kidneys.

\section{SIRT1 and autophagy in the diabetic kidney}

Silent information regulator T1 (SIRT1), a NAD+-dependent deacetylase, is the second major nutrient-sensing pathway implicated as a positive regulator of autophagy (Fig. 2). However, the mechanism of SIRT1-mediated autophagy induction is less well-understood. SIRT1 forms a molecular complex with essential components of the autophagy machinery, such as ATG5, ATG7, and LC3, and in an NAD-dependent fashion and directly deacetylate these components (Lee et al. 2008). Moreover, SIRT1 can interact with and deacetylate the transcription factor forkhead box O3 (FoxO3), resulting in enhanced expression of BCL2/adenovirus E1B $19 \mathrm{kDa}$ interacting protein 3 (BNIP3), and promote autophagy (Kume et al. 2010). SIRT1 functions as an intracellular energy sensor by monitoring the $\mathrm{NAD}+$ concentration and regulates in vivo metabolic changes and redox stresses. SIRT1 is abundantly expressed in mouse renal medullary interstitial cells, and knocking down its expression substantially reduced cellular resistance to oxidative stress, whereas pharmacologic activation of SIRT1 improved cell survival in response to oxidative stress (He et al. 2010).

Similar to AMPK, SIRT1 expression is decreased in the kidneys of experimental type 1 and type 2 diabetic animals (Li et al. 2010a, Chuang et al. 2011). Glomerular expression of SIRT1 was also reduced in patients with DN (Chuang et al. 2011). Increasing SIRT1 activity by treatment with SIRT1 activators, such as resveratrol, reduced diabetic kidney changes in both type 1 and type 2 experimental diabetes.

Published by Bioscientifica Ltd 
Resveratrol induced a partial reversal of collagen type IV and fibronectin protein induction and ameliorated kidney injury in STZ-induced diabetic rats (Wu et al. 2012). Resveratrol treatment in $d b / d b$ mice also decreased albuminuria, ameliorated glomerular matrix expansion and inflammation, and reversed the increase in renal apoptotic cells and oxidative stress (Kim et al. 2013). Resveratrol also reduced high glucose-mediated oxidative stress and senescence in mesangial cells (Xu et al. 2012, Zhang et al. 2012), and protected podocytes from AGE-induced apoptosis (Chuang et al. 2011). Moreover, treatment with resveratrol resulted in the reduction of tubulointerstitial fibronectin accumulation as well as macrophage infiltration in the renal interstitial lesions of $d b / d b$ mice, and ameliorated the enhanced mitochondrial biogenesis with manganese-superoxide dismutase dysfunction in proximal tubular cells (Kitada et al. 2011b). However, resveratrol treatment did not alter AMPK activation nor SIRT1 expression in the kidney, suggesting that these protective effects are through improvement of oxidative stress via AMPK/SIRT1-independent pathway. Increased expression of SIRT1 in pancreatic $\beta$ cells enhances insulin secretion in response to glucose and improves glucose tolerance (Moynihan et al. 2005). SIRT1 also stimulates insulin signaling pathways in insulin-sensitive organs by repressing the transcription of PTP1B protein tyrosine phosphatase 1B (PTP1B), which acts as a negative regulator of insulin signaling, and regulating insulin-induced tyrosine phosphorylation of insulin-receptor substrate 2 (IRS2) (Sun et al. 2007, Zhang 2007). Thus, like AMPK, SIRT1 in the kidney is cytoprotective and inhibition of SIRT1 contributes to renal injury associated with $\mathrm{DN}$ via negative regulation of autophagy. SIRT1 also has a positive role in insulin action by inducing insulin secretion and repressing negative regulators of insulin signaling. These findings suggest a therapeutic promise of targeting SIRT1 in insulin resistance and diabetic kidney injury.

\section{Autophagy in renal cells}

The mechanisms of autophagy in kidney function and pathology remain still largely understudied. We are just beginning to appreciate the complexity of the autophagic pathway. A growing body of evidence implicates the importance of autophagy in both the maintenance of kidney homeostasis and disease pathogenesis. Much of the current insight has been gained from investigations in renal cells in culture and in complementary studies carried out in animal models. The regulation and function of autophagy in the kidney are likely cell type and context specific. In the following, we discuss studies in four resident renal cell types, podocytes and glomerular mesangial and endothelial cells, which participate in the vital functions of glomerular filtration, and renal tubular epithelial cells (Fig. 3). These highly specialized cell types are targets of diabetic kidney injury.

\section{Podocytes and autophagy in the diabetic kidney}

Podocytes are highly differentiated glomerular epithelial cells with interdigitating foot processes that line the outer aspect of the GBM and envelope the glomerular capillaries to form the kidney filtration barrier (Fig. 3). Injury and loss of podocytes lead to albuminuria, a hallmark of DN. A decrease in the number of podocytes is a predictor for the progression of kidney diseases, including DN (Wolf et al. 2005). Given that postmitotic cells such as podocytes have a very limited capacity for cell division and replacement, self-repair mechanisms are vital to maintain homeostasis. Autophagy is a fundamental cellular homeostatic process that cells use to degrade and recycle cellular proteins and remove damaged organelles. Evidence shows that podocytes have a high level of basal autophagy, which may serve as a mechanism for their maintenance of cellular homeostasis (Hartleben et al. 2010, Fang et al. 2013). Podocyte-specific deletion of the Atg5 gene led to the development of glomerulopathy in aging mice, with oxidized and ubiquitinated protein accumulation and ER stress in podocytes that ultimately resulted in podocyte loss, increased proteinuria and glomerulosclerosis (Hartleben et al. 2010). Furthermore, the induction of proteinuria in mice with podocyte-specific deletion of the Atg 5 gene, induced by puromycin aminonucleoside or adriamycin, led to more severe albuminuria, loss of podocytes, and glomerulosclerosis, compared with control mice (Hartleben et al. 2010). Therefore, these studies underscore the importance of constitutive and induced autophagy as major protective mechanisms against aging and podocyte injury. Deficiency in autophagy increases susceptibility to the development of glomerular diseases, and autophagy represents a stress-adaptive response of podocytes that is cytoprotective against glomerular disease.

Studies carried out in mice with podocyte-specific mTORC1 activation induced by conditional deletion of an upstream negative regulator TSC1 gene products (Tsc1) in podocytes recapitulated many features of DN, such as podocyte injury and loss, proteinuria, GBM thickening, mesangial expansion, and glomerulosclerosis (Inoki et al. 2011). On the other hand, reduction of mTORC1 in diabetic mice through podocyte-specific heterozygous deletion of Raptor, an essential component

Published by Bioscientifica Ltd 


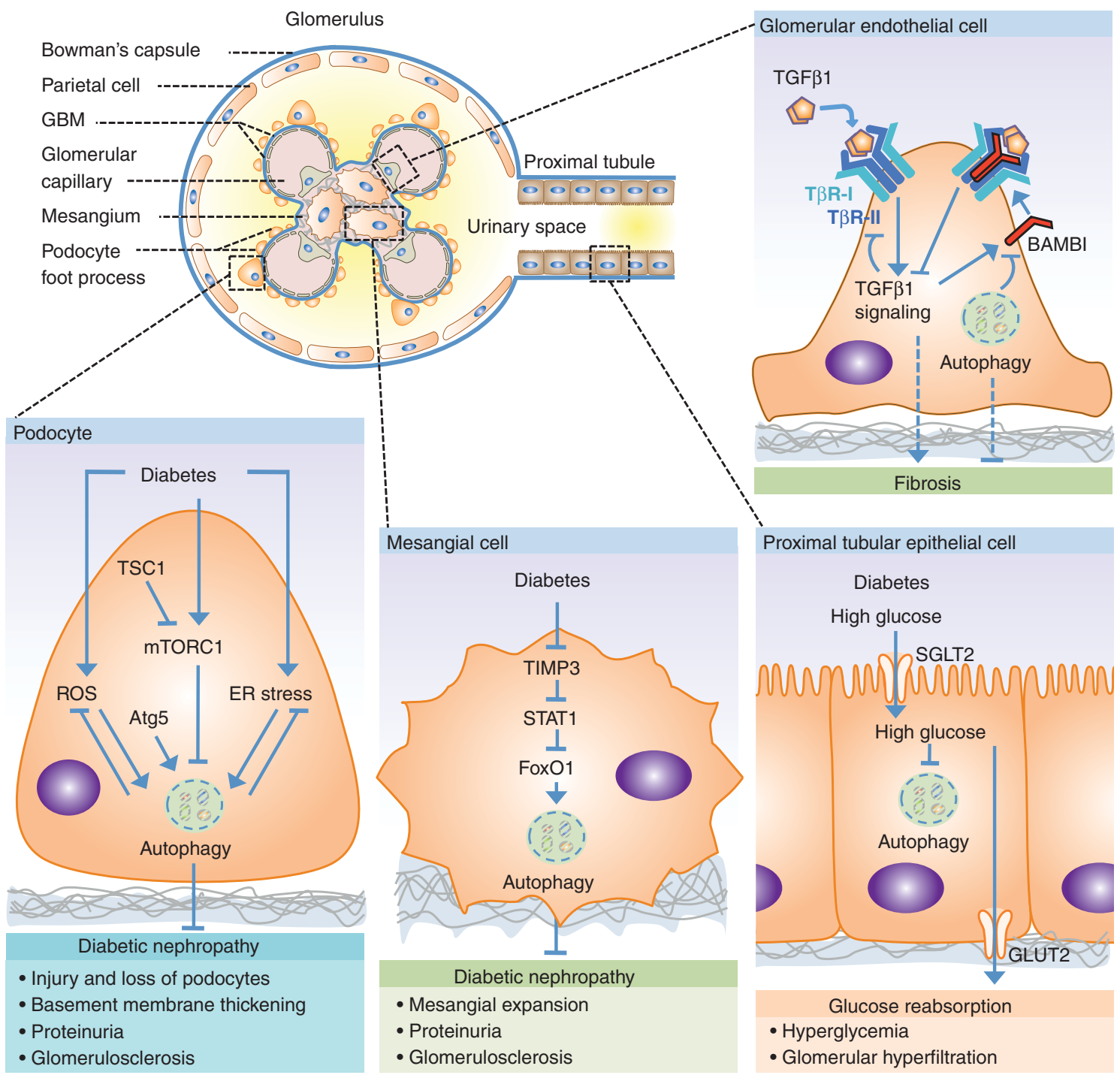

\section{Figure 3}

Schematic representation of the glomerulus and proximal tubule and summary of autophagy-mediated pathways in renal cells involved in diabetic nephropathy (DN). The highly specialized podocyte and its foot processes surround the glomerular basement membrane (GBM) and cover the glomerular capillary tuft. Mesangial cells occupy the centrilobular region called the mesangium. The Bowman's capsule is lined by parietal epithelial cells. Approximately $180 \mathrm{I}$ of renal plasma is filtered by the glomerulus daily. The resultant filtrate flows through the tubules with reabsorption and secretion of ions, carbohydrates, amino acids, and

of mTORC1, significantly reduced proteinuria, mesangial matrix expansion, and glomerulosclerosis, and suppressed the development of DN in both type 1 and type 2 diabetic animals (Gödel et al. 2011, Inoki et al. 2011). These findings indicate that $\mathrm{mTORC} 1$ activation in podocytes is associated with the development of $\mathrm{DN}$, whereas reduction in podocyte mTORC1 activity protects podocytes and inhibits progressive DN, suggesting that mTOR Printed in Great Britain eventual elimination of urine. Under normal condition, the ultrafiltrate is virtually free of plasma protein. mTORC1, mechanistic target of rapamycin complex 1; TSC1, tuberous sclerosis complex 1; ROS, reactive oxygen species; Atg, autophagy-related gene; ER, endoplasmic reticulum; TIMP3, tissue inhibitor of metalloproteinase-3; FOXO1, forkhead box protein 01; SGLT2, sodium glucose cotransporter 2; GLUT2, glucose transporter 2; TGF $\beta 1$, transforming growth factor beta 1; T $\beta R 1$, TGF $\beta$ type 1 receptor, BAMBI, bone morphogenetic protein and activin receptor membrane bound inhibitor.

suppression is a potential therapeutic strategy to prevent DN. Treatment with the mTORC1 inhibitor rapamycin restores autophagic activity in podocytes exposed to highglucose conditions (Fang et al. 2013). Thus, mTORC1 activation may be responsible for suppressing autophagy in podocytes under diabetic conditions, and the protective effects from reduction in podocyte mTORC1 activity may be due to the restoration of autophagic activity. 
Interestingly, podocyte-specific deletion of mTORC1 in nondiabetic mice also induced proteinuria and progressive glomerulosclerosis (Gödel et al. 2011, Inoki et al. 2011). The simultaneous deletion of both mTORC1 and mTORC2 in the mouse podocytes aggravated the glomerular lesions (Gödel et al. 2011). These findings demonstrate the importance of basal mTORC1/mTORC2 activities for maintaining podocyte homeostasis. Hence, both excessive and insufficient mTOR activity can be deleterious to the podocytes. Further investigations are necessary to clarify the relationship between autophagy and mTOR signaling inducing podocyte dysfunction under diabetic conditions.

\section{Mesangial cells and autophagy in the diabetic kidney}

Expansion of the cellular and matrix components in the mesangium is a hallmark of type 1 and type $2 \mathrm{DN}$. Mesangial cell proliferation and hypertrophy together with excessive accumulation of ECM proteins within the mesangium are prominent features, which eventually lead to glomerulosclerosis (Kanwar et al. 2011). The function of autophagy in the mesangial cells is just beginning to be uncovered. We reported that autophagy contributed to the survival of mesangial cells. Under serum deprivation conditions, autophagy was induced by TGF $\beta 1$ in mesangial cells via TAK1 and PI3K-AKT-dependent pathways, and autophagy enhanced cell survival by inhibiting mesangial cells from undergoing apoptosis (Ding et al. 2010b). We also reported that autophagy negatively regulated ECM production in mesangial cells by promoting the degradation of intracellular type 1 collagen (Kim et al. 2012a). These data suggest a novel intracellular mechanism by which collagen protein levels may be regulated through autophagic degradation to suppress renal fibrosis.

Studies implicate dysregulated autophagy in the pathogenesis of DN. However, little is known regarding the function of autophagy in mesangial cells under diabetic conditions. A recent report has provided evidence that autophagy may be inhibited through downregulation of the tissue inhibitor of metalloproteinase-3 (TIMP3). In both STZ-induced diabetic mice and in patients with DN, renal expression of TIMP3 is reduced (Fiorentino et al. 2013). Reduced expression of TIMP3 results in STAT1dependent inhibition of transcription factor FOXO1, which in turn suppresses the expression of protective autophagy genes to induce glomerular damage and proteinuria. Studies carried out in kidney biopsies of patients with DN confirmed significant reduction in the expression of TIMP3, FOXO1, and FOXO1-target genes involved in autophagy, whereas STAT1 expression was increased (Fiorentino et al. 2013). Furthermore, knockdown of TIMP3 in mesangial cells, either by shRNA or genetic deletion in primary mesangial cells obtained from Timp3-null mice, recapitulated FOXO1 downregulation in vivo and inhibition of autophagy (Fiorentino et al. 2013). These studies suggest that in the diabetic kidney, TIMP3 deficiency-induced reduction in autophagy through FOXO1 attenuated the protective function of autophagy and contributed to diabetic kidney disease.

\section{Glomerular endothelial cells and autophagy}

Studies suggest that endothelial dysfunction is involved in the development of diabetic and nondiabetic glomerular injury and renal fibrosis (Stehouwer 2004). Advanced diabetic glomerulopathy in humans exhibits evidence of endothelial dysfunction in the glomerulus, such as thrombotic microangiopathy, including glomerular capillary microaneurysms and mesangiolysis (Nakagawa et al. 2011). In animal model of STZ-induced diabetes in endothelial nitric oxide synthase (eNOS)-knockout mice, severe endothelial dysfunction due to deficiency of eNOS exacerbates diabetic kidney damage with features that resemble human DN (Nakagawa et al. 2011). Few studies have examined the role of autophagy in glomerular endothelial cells. Xavier et al. (2010) demonstrated that bone morphogenetic protein and activin receptor membrane-bound inhibitor (BAMBI), a competitive receptor antagonist for the TGF $\beta$ receptor family, is expressed in glomerular endothelial cells and regulated by autophagy. BAMBI interferes with the complex formation of TGF $\beta$ type 1 and 2 receptors (T $\beta R 1$ and T $\beta R 2$ ) and blocks TGF 1 signal transduction, thereby inhibiting fibrosis (Fig. 3). Interestingly, TGF $\beta$ treatment upregulated $B A M B I$ mRNA in glomerular endothelial cells and downregulated T $\beta$ R2, perhaps as a negative feedback loop. Induction of autophagy resulted in BAMBI protein degradation. Therefore, these studies point to the existence of a complex network of positive and negative regulation of TGF $\beta$ through autophagy. Further investigations are required to elucidate the functional role of autophagy in glomerular endothelial cells in modulating TGF $\beta 1$ signaling and endothelial dysfunction in the development of diabetic kidney disease and fibrosis.

\section{Proximal tubular epithelial cells and autophagy in the diabetic kidney}

Renal tubular epithelial cells, unlike podocytes, display a low level of basal autophagy under normal conditions (Liu et al. 2012). However, mice with proximal tubulespecific deletion of Atg5 gene gradually developed

Published by Bioscientifica Ltd 
deformed mitochondria and accumulation of p62- and ubiquitin-positive cytosolic inclusion bodies, leading to cellular hypertrophy and eventual degeneration of proximal tubule cells at 9 months of age (Kimura et al. 2011). Moreover, $\operatorname{Atg} 5$ deficiency exacerbated ischemia/ reperfusion (I/R) injury with increased proximal tubule cell apoptosis and accumulation of p62- and ubiquitinpositive cytosolic inclusions (Liu et al. 2012). Taken together, these studies suggest that autophagy is important for maintaining proximal tubule cell homeostasis and protection against aging and $\mathrm{I} / \mathrm{R}$ injury.

Hyperglycemia has been shown to inhibit cellular autophagy, associated with an increase in p62/SQSTM1, in proximal and distal tubular cells of both type 1 and type 2 diabetic animals (Barbosa et al. 1992, Han et al. 1997, Kitada et al. 2011a). The apically expressed sodium-glucose cotransporter 2 (SGLT2) promotes high-capacity glucose uptake in the proximal tubule (Fig. 3). The inhibition of SGLT2 increases renal excretion of glucose, thereby lowering blood glucose levels, and pharmacological inhibitors that block SGLT2 are being developed as potential antidiabetic drugs (Nair \& Wilding 2010). Knockout of Sglt2 attenuated the STZ-induced renal accumulation of p62/SQSTM1, indicating a role of SGLT2-induced glucose uptake resulting in inhibition of autophagy (Vallon et al. 2013). Also, SGLT2 deficiency attenuated hyperglycemia and glomerular hyperfiltration due to STZ-induced diabetes, but did not alter the expression of the basolateral glucose transporter 2 (GLUT2). However, SGLT2 deficiency did not attenuate fibrosis markers, such as fibronectin and Sirius redsensitive renal collagen, in STZ-induced diabetes (Vallon et al. 2013). The findings of Sglt2 knockout dissociating hyperglycemia/hyperfiltration response from renal fibrosis in STZ-induced diabetes are not readily explained.

SIRT1 is an important autophagy mediator in the kidney. Using proximal tubule-specific Sirt1 knockout and Sirt1-transgenic mice, a recent report (Hasegawa et al. 2013) has suggested that SIRT1 in proximal tubules affects glomerular function and protects against diabetic renal damage. Reduced SIRT1 expression in proximal tubules led to the downregulation of SIRT1 and upregulation of the tight junction protein Claudin- 1 in podocytes and contributed to albuminuria. Moreover, in $d b / d b$ or STZinduced diabetic mice, the expression of SIRT1 in proximal tubules was downregulated before the occurrence of albuminuria. These findings indicate that renal tubular SIRT1 attenuates albuminuria by epigenetically suppressing Claudin-1 expression in podocytes. Although autophagy activity was not directly assessed in the above studies by Hasegawa et al. (2013) given that SIRT1 is a positive regulator of autophagy in the kidney, the findings suggest the possible mechanism for a protective role of proximal tubule SIRT1 against diabetes-induced albuminuria through induction of autophagy.

\section{AGEs and autophagy in the diabetic kidney}

Hyperglycemia-induced kidney injury causes alterations in intracellular metabolism, including generation of AGEs, and renal accumulation of AGEs contributes to the pathogenesis of DN (Kanwar et al. 2011). Extracellular AGEs are formed by irreversible cross-linking of glucose with ECM proteins. In high-glucose milieu, extracellular AGEs, through their interaction with receptor for AGEs, and intracellular AGEs induce oxidative stress and modulate various cellular events, such as the generation of reactive oxygen species (ROS) and activation of PKC (Fig. 2). A recent report has suggested a role of autophagic clearance of AGEs in the amelioration of diabetic vascular complications including kidney dysfunction (Peng et al. 2011). In diabetic mice, treatment with an inducer of hepatocyte growth factor (HGF) reduced serum level of AGEs via autophagic-lysosomal activity and improved kidney function. Recombinant mouse HGF enhanced the endocytosis and autophagic clearance of AGEs (Peng et al. 2011). These studies suggest that autophagy may exert renoprotective effects by promoting clearance of AGEs and preventing renal accumulation of AGEs in diabetes.

\section{Oxidative stress, autophagy, and DN}

Altered intracellular metabolism related with hyperglycemia is implicated in the pathogenesis of DN. Oxidative stress occurs as a consequence of the imbalance between ROS generation and local antioxidant defenses (Tan et al. 2007). The production of ROS in the kidney is enhanced by high-glucose concentrations and is associated with cell dysfunction (Koya et al. 2003). Sources of ROS in the diabetic kidney include auto-oxidation of glucose, advanced glycation, polyol pathway flux, and activation of PKC. Mitochondrial dysfunction and mitochondrial respiratory chain deficiencies also generate ROS. Normalizing levels of mitochondrial ROS have been shown to prevent glucose-induced activation of PKC and formation of AGEs (Nishikawa et al. 2000). A recent study in podocytes has revealed that within $24 \mathrm{~h}$ of exposure to high glucose condition increases in ROS generation and autophagy induction, and treatment with antioxidant $\mathrm{N}$-acetylcysteine inhibited the high glucose-induced

Published by Bioscientifica Ltd 
autophagy (Ma et al. 2013). These findings suggest that the acute exposure to high glucose-induced autophagy, which is mediated through the generation of ROS in podocytes. Exposure of podocytes to angiotensin II (ANG II) also enhanced ROS generation and induced autophagy, and treatment with antioxidants inhibited ANG II-induced autophagy (Yadav et al. 2010). Diabetic kidneys display the evidence of mitochondrial damage such as abnormal mitochondrial morphology with marked swelling and disintegration of cristae (Kitada et al. 2011a). Autophagymediated clearance of damaged mitochondria would reduce ROS and restore homeostasis. Thus, increase in ROS induces autophagy, presumably as an adaptive response to cellular stress, and in turn autophagy leads to reduction in ROS to protect the kidney under diabetic conditions (Fig. 2). Studies by Fang et al. (2013) revealed that prolonged exposure to high glucose resulted in defective autophagy in podocytes and the restoration of autophagy activity attenuated diabetic glomerular damage, suggesting that the reduction in autophagy activity may facilitate the podocyte injury.

\section{ER stress, autophagy, and DN}

The ER is not only involved in protein synthesis and maturation process involving proper folding and assembly but also comprises a major source for the autophagic isolation membrane (Hamasaki et al. 2013). ER stress can induce autophagy and has been linked with the pathogenesis of diabetes and DN (Hummasti \& Hotamisligil 2010, Zhang et al. 2014). Accumulation of misfolded proteins in the ER induces the unfolded protein response (UPR) which represents the major ER stress pathway (Walter \& Ron 2011). The UPR-related proteins, protein kinase RNA-like ER kinase (PERK), and activating transcription factor-6 (ATF6) have been reported to induce autophagy, while inositol-requiring enzyme 1 (IRE1) acts as a negative regulator of autophagy (Kroemer et al. 2010). PERK promotes the transcription of LC3 and ATG5 via transcription factors ATF4 and CCAAT/enhancer-binding protein (C/EBP) homologous protein, respectively, whereas IRE1 inhibits autophagy via its downstream effector X-boxbinding protein 1 (XBP1) (Kroemer et al. 2010, Rouschop et al. 2010). The inhibition of IRE1 enhances autophagy induction, and mice lacking XBP1 exhibit increased levels of baseline autophagy (Kroemer et al. 2010). It is possible that IRE1/XBP1-dependent signals function to curtail excessive autophagy induced via the PERK and possibly ATF6. Thus, IRE1 inhibition of autophagy may serve as a mechanism to control ER stress-induced autophagy.
High glucose and free fatty acids have been shown to induce ER stress and UPR in podocytes and subsequent apoptosis (Sieber et al. 2010, Cao et al. 2014). Exposure of renal tubular epithelial cells to high glucose and albumin also induce ER stress and apoptosis (Ohse et al. 2006, Lindenmeyer et al. 2008). Moreover, increased renal tubular expression of genes involved in ER stress is observed in kidney biopsies from patients with DN and proteinuria (Lindenmeyer et al. 2008). Defective autophagy has been implicated in the pathogenesis of diabetic kidney disease, and the impairment of autophagic activity may lead to further increase in ER stress and subsequent tissue injury. Recent studies have suggested that chemical chaperones that enhance protein folding can mitigate diabetic injury by reduction of ER stress, an effect which may be mediated through restoration of defective autophagy. Tauroursodeoxycholic acid (TUDCA) is one such chemical chaperone shown to prevent AGE-induced podocyte apoptosis by blocking an ER stress-mediated apoptotic pathway (Chen et al. 2008). Furthermore, TUDCA treatment was associated with decreased albuminuria, attenuated podocyte injury and glomerular damage, and restored autophagy in diabetic mice (Fang et al. 2013). Treatment with phenyl butyric acid, a chemical chaperone, also reduced proteinuria and inhibited the expression of ER stress markers PERK and glucoseregulated protein 78 in STZ-induced diabetic rats, and reduced the expression of phosphorylated c-JUN NH(2)terminal kinase, monocyte chemoattractant protein-1, and TGFB1 (Qi et al. 2011). Taken together, these studies suggest that hyperglycemia-stimulated ER stress induces autophagy, probably as a stress adaptive response, and the renoprotective effects of the chemical chaperones by reducing ER stress may be facilitated through restoration of defective autophagy. However, further studies are needed that establish a causal relationship to directly link autophagy and reduction of ER stress by the chemical chaperones to mitigate diabetic renal injury.

\section{Hypoxia, autophagy, and DN}

Hypoxia-induced renal injury has been proposed as a mechanism contributing to the development of DN. Hypoxia is generally attributed to chronic ischemia, that may arise from intrarenal vasoconstriction following local activation of RAS or decreased NO activity (Kanwar et al. 2011). In addition, structural impairment of renal blood flow, due to presence of interstitial fibrosis surrounding the peritubular capillaries, can restrict tissue oxygen delivery. Hypoxia can also occur in acute kidney injury, for instance,

Published by Bioscientifica Ltd. 
as a consequence of I/R injury. Hypoxia induces autophagy. Exposure of cultured renal proximal tubular cells to either $1 \% \mathrm{O}_{2}$ (hypoxia) or $0 \% \mathrm{O}_{2}$ followed by recovery/ reperfusion period (I/R) induced autophagy (Jiang et al. 2010). Blocking autophagy with 3-methyladenine (3-MA), Beclin 1-siRNA, or Atg5-siRNA enhanced hypoxia-induced renal tubular cell apoptosis. These findings were also confirmed in vivo. I/R injury in mice induced autophagy, and blockade of autophagy worsened renal I/R injuryinduced renal dysfunction, histology, and tubular apoptosis (Jiang et al. 2010). Therefore, these findings support that autophagy provides a protective mechanism against hypoxia-induced apoptosis and kidney injury.

Hypoxia induces autophagy via hypoxia inducible factor-1 alpha (HIF1 $\alpha$ ), a transcription factor that is activated and plays an essential role in cellular and systemic responses to hypoxia. HIF1 $\alpha$ activates the transcription of BNIP3 and BNIP3-like (BNIP3L) to disrupt the interaction of Beclin1 and BCL2, liberating Beclin 1 from BCL2 in cells and thereby inducing autophagy (Bellot et al. 2009). SIRT1 deacetylates and positively regulate the transcription factor FOXO3, which also upregulates the transcription of BNIP3 and enhances BNIP3-dependent autophagy (Kume et al. 2010). The involvement of HIF1 $\alpha$-mediated autophagy induction in the kidney has been demonstrated in a mouse model of polycystic kidney disease, a genetic disorder characterized by innumerable cyst formation in the kidney resulting in localized areas of hypoxia (Belibi et al. 2011). Calorie restriction has also been shown to increase autophagic activity and protect the aging kidney from hypoxia-induced oxidative stress via SIRT1-FOXO3 axis (Kume et al. 2010). Evidence suggests that hypoxia probably causes functional impairment in the mitochondria of the renal tubular cells and diabetic rat kidneys display increased mitochondrial uncoupling which would result in increased $\mathrm{O}_{2}$ consumption and reduced tissue $\mathrm{O}_{2}$ availability (Friederich et al. 2008). Thus, hypoxiainduced mitochondrial dysfunction and intracellular accumulation of ROS may contribute to the development of diabetes-induced kidney damage. An important role of autophagy may be to remove the damaged mitochondria and reduce ROS, thereby providing a protective mechanism against hypoxia-induced kidney injury.

\section{Autophagy and RAS}

Numerous studies have examined the effects of the RAS on protein synthesis/turnover, cellular hypertrophy, proliferation, and apoptosis in diabetic kidneys. An activated intrarenal RAS has been implicated in the pathogenesis of DN. Blockade of the RAS with agents such as an angiotensin-converting enzyme (ACE) inhibitor and ANG II type $1\left(\mathrm{AT}_{1}\right)$ receptor blockers, through inhibition with local production and/or local effects of ANG II, exerts renoprotective effects (Lu et al. 2013). ANG II generated in the circulation will diffuse to tissues where it can bind to its main receptor $\mathrm{AT}_{1}$ to exert its effects. However, it is believed that most renal $\mathrm{AT}_{1}$ receptors are exposed to locally generated ANG II and uptake from plasma contributes very little to the renal ANG II content (van Kats et al. 2001). ANG II has been shown to induce autophagy. In podocytes, ANG II enhances the expression of autophagic proteins, LC3 and Beclin 1, and promotes formation of autophagosomes through increased generation of ROS (Yadav et al. 2010). RAS blockade is not entirely protective in diabetic renal injury, which may be due to, at least in part, the inhibitory effect of ANG $\mathrm{II}-\mathrm{AT}_{1}$ receptor blockade on autophagy contributing to a reduced protective action. Future investigations are necessary to explore this possibility.

The (pro)renin receptor (PRR) is a recently identified transmembrane protein that interacts with prorenin to exert renin activity via nonproteolytic activation of prorenin and activation of the local tissue, but not the circulatory RAS. In addition, PRR has been shown to mediate RAS-independent signal transduction via activation of ERK1/2 in cells and is an accessory subunit of the vacuolar $\mathrm{H}(+)$-ATPase, suggesting that it has functions beyond the activation of the local RAS. In STZ-induced diabetes, blockade of prorenin binding to its receptor suppressed proteinuria, glomerulosclerosis, and renal production of ANG I and II without affecting the circulatory RAS, indicating a critical contribution of the PRR to the pathogenesis of DN (Ichihara et al. 2006, Takahashi et al. 2007). However, others were not able to confirm the protective effects of PRR blockade in models of hypertension or kidney damage (Muller et al. 2008, Nguyen \& Muller 2010). Podocytes express PRR, but its function in these cells is not well-known. A recent study has revealed a significant contribution of the PRR and local tissue RAS to the pathogenesis of diabetes-induced retinal inflammation (Satofuka et al. 2009), a model of diabetic microvascular complication. On the other hand, mice with specific deletion of PRR in podocytes displayed foot process effacement with reduced and altered localization of the slit-diaphragm proteins, nephrin and podocin, and died of kidney failure and severe proteinuria within 2-4 weeks of birth (Oshima et al. 2011, Riediger et al. 2011). Podocyte-specific PRR deletion also resulted in abnormal processing of multivesicular bodies

Published by Bioscientifica Ltd. 
and enrichment of autophagosomal and lysosomal markers, LC3 and LAMP2 respectively (Oshima et al. 2011, Riediger et al. 2011), indicating a functional block in autophagosome-lysosome fusion. Taken together, these results suggest that the $P R R$ is essential for the maintenance of normal podocyte structure, function, and survival by maintaining autophagy and protein-turnover machinery, indicating PRR function that is independent of modulating the RAS. Hence, it is likely that the PRR functions are complex and we do not yet fully understand the role of PRR in disease. Further studies using tissuespecific ablation of $P R R$ or administration of a specific PRR antagonist are warranted.

\section{Autophagy and kidney fibrosis}

Diabetic kidney disease is characterized by the accumulation of the ECM in the glomerular and tubulointerstitial compartments, resulting in progressive kidney fibrosis that leads to irreversible loss of tissue and decline in kidney function. The development of fibrosis represents the final common response to injury that ultimately leads to end-stage kidney failure in both type 1 and type 2 diabetes. TGF $\beta 1$ plays a central role in the pathogenesis of tissue fibrosis in the kidney. Overexpression of TGF $\beta 1$ in renal tubular epithelial cells, using a tetracyclineinducible transgenic mouse model, resulted in widespread peritubular fibrosis and decomposition of tubular cells with induction of autophagy (Koesters et al. 2010). Kidney injury induced by unilateral ureteral obstruction (UUO), a model of progressive renal fibrosis, resulted in tubular epithelial loss and tubulointerstitial fibrosis accompanied by enhanced autophagy in the obstructed tubules (Li et al. 2010b, Forbes et al. 2011). A recent study indicates that oxidative stress leading to mitochondrial damage, autophagy-dependent cell death, and apoptosis is an important mechanism of tubular decomposition in UUO injury (Xu et al. 2013). On the other hand, inhibition of autophagy by 3-MA enhances tubular cell apoptosis and tubulointerstitial fibrosis in the obstructed kidney after UUO, suggesting that autophagy is renoprotective (Kim et al. 2012b). Thus, autophagy has dual roles, capable of promoting cell survival or cell death, the latter thought to be due to excessive autophagic activity leading to type II programed cell death. Our recent studies uncovered a novel role of autophagy in the negative regulation of collagen accumulation through autophagic degradation pathway (Kim et al. 2012a). Moreover, kidney injury following UUO potently induces autophagy and negatively regulates TGF $\beta 1$ expression and that deficiency of autophagic protein LC3 leads to increased collagen deposition and mature forms of TGF $\beta 1$ in obstructed kidneys in LC3-null (LC3 ${ }^{-/-}$) mice (Ding et al. 2014). These data suggest a novel intracellular mechanism by which collagen and TGF- $\beta 1$ protein levels may be regulated through autophagic degradation for suppression of renal fibrosis.

\section{Therapeutic targeting of autophagy}

Impairment of autophagic activity has been implicated in the pathogenesis of diabetic kidney disease. Hence, targeting the various components involved in the autophagic pathway may be a promising novel therapeutic strategy for the treatment of DN. Herein, we reviewed three major nutrient-sensing signal pathways, mTOR, AMPK, and SIRT1, which modulate autophagic activity and contribute to the development of DN. Inhibition of the mTOR pathway is an attractive target for amelioration of diabetic kidney injury based on the preclinical studies. However, it is important to note that while mTORC1 inhibition activates autophagy which is renoprotective, prolonged mTORC1 inhibition can be deleterious possibly due to the disruption of autophagic flux. There has been much interest in exploring the use of Rapamycin, a well-known inhibitor of mTORC1 and a potent activator of autophagy, as a drug for treatment of DN. However, some studies have reported that long-term inhibition of mTORC1 signaling by treatment with rapamycin can exacerbate glomerular damage. Development of de novo or worsening proteinuria is wellrecognized in patients with chronic use of rapamycin (Fervenza et al. 2004, Lieberthal \& Levine 2009). Thus, therapy with rapamycin and other mTOR inhibitors can be a double-edged sword, with both favorable and unfavorable consequences, and should be approached with caution. Targeting the AMPK and SIRT1 with activating agents such as resveratrol, metformin, and AICAR is also being explored. Both AMPK and SIRT1 are positive regulators of autophagy. AMPK can also cross-talk with mTORC1 signaling and induce autophagy by inhibiting mTORC1 activity. Therefore, a balance between mTORC1 and AMPK is important for subsequent autophagy initiation and AMPK activation may be a target for restoring autophagy activity in diabetic kidneys.

Resveratrol is a natural polyphenolic compound found in red wine that has been shown to have the potential protective effects in diabetic cardiovascular and renal diseases, though not without controversy (Kitada et al. 2011b, Turan et al. 2012). Resveratrol is an activator

Published by Bioscientifica Ltd 
of SIRT1 and AMPK pathways, thereby activating autophagy, and also has potent antioxidant properties such as a scavenger of ROS. Remarkably, beneficial effects of resveratrol have been the subject of heated debate including the speculation that the cellular effects are not through direct SIRT1 binding. Recent research has provided evidence indicating that resveratrol directly activates SIRT1 and that SIRT1 is required for AMPK activation and the beneficial effects in cells are similar to those caused by calorie restriction (Price et al. 2012). Nutrient-depleted condition is a potent stimulator of autophagy to overcome long-term periods of starvation. Calorie restriction has been shown to exert a renoprotective effect in type 1 (Tikoo et al. 2007) and type $2 \mathrm{DN}$ (Kitada et al. 2011a) and restore autophagy activity. Thus, calorie restriction, which activates autophagy, may be an effective therapeutic strategy to prevent DN. The use of chemical chaperones, such as TUDCA, which enhance ER protein folding capacity and thereby reduce ER stress and restore autophagy activity may also be a therapeutic approach to mitigate diabetic kidney injury.

\section{Conclusions}

$\mathrm{DN}$ is the most common cause of end-stage kidney disease worldwide, and is associated with a significant increase in morbidity and mortality in patients with both type 1 and type 2 diabetes. Central to the current approaches to treatment of DN is the blockade of the RAS with drugs such as ACE inhibitors and ANG II receptor blockers, whose renoprotective effects have been impactful in retarding progression of many chronic kidney diseases. In addition, the importance of optimal blood pressure and glycemic control, as well as lipid control is wellestablished. However, the current therapies are not always effective and, at best, they slow, but not prevent, the progression of DN. Hence, there is a critical need for the development of new therapeutics directed at preventing the development and progression of diabetic kidney disease. Dysregulated autophagy is implicated in the pathogenesis of $\mathrm{DN}$ and evidence suggests that targeting the autophagic pathway to activate and restore autophagy activity may be renoprotective. Autophagy plays a critical role in removing protein aggregates and damaged organelles and thereby, promoting cell survival and tissue homeostasis. However, excessive autophagy can also contribute to cell death or, in certain circumstances, promote development of de novo or worsening proteinuria. Thus, autophagy may be deleterious. Future investigations are necessary to uncover the precise functional roles of autophagy in glomerular and tubular injury related with DN that will further advance our understanding of the role of autophagy in the kidney and guide potential therapies.

\section{Declaration of interest}

The authors declare that there is no conflict of interest that could be perceived as prejudicing the impartiality of this review.

\section{Funding}

Supported in part by the National Institutes of Health grants R01-DK57661, R01-HL079904, and P01-HL114501 to M E C.

\section{References}

Alers S, Löffler AS, Wesselborg S \& Stork B 2012 Role of AMPK-mTOR-Ulk1/2 in the regulation of autophagy: cross talk, shortcuts, and feedbacks. Molecular and Cellular Biology 32 2-11. (doi:10.1128/MCB.06159-11)

Arias E \& Cuervo AM 2010 Chaperone-mediated autophagy in protein quality control. Current Opinion in Cell Biology 23 184-189. (doi:10.1016/j.ceb.2010.10.009)

Barbosa Júnior Ade A, Zhou H, Hültenschmidt D, Totovic V, Jurilj N \& Pfeifer U 1992 Inhibition of cellular autophagy in proximal tubular cells of the kidney in streptozotocin-diabetic and uninephrectomized rats. Virchows Archiv. B, Cell Pathology Including Molecular Pathology 61 359-366.

Belibi F, Zafar I, Ravichandran K, Segvic AB, Jani A, Ljubanovic DG \& Edelstein CL 2011 Hypoxia-inducible factor- $1 \alpha$ (HIF-1 $\alpha$ ) and autophagy in polycystic kidney disease (PKD). American Journal of Physiology. Renal Physiology 300 F1235-F1243. (doi:10.1152/ajprenal.00348.2010)

Bellot G, Garcia-Medina R, Gounon P, Chiche J, Roux D, Pouysségur J \& Mazure NM 2009 Hypoxia-induced autophagy is mediated through hypoxia-inducible factor induction of BNIP3 and BNIP3L via their BH3 domains. Molecular and Cellular Biology 29 2570-2581. (doi:10.1128/ MCB.00166-09)

Brenner BM, Cooper ME, de Zeeuw D, Keane WF, Mitch WE, Parving HH, Remuzzi G, Snapinn SM, Zhang Z, Shahinfar S et al. 2001 Effects of losartan on renal and cardiovascular outcomes in patients with type 2 diabetes and nephropathy. New England Journal of Medicine 345 861-869. (doi:10.1056/NEJMoa011161)

Calcutt NA, Cooper ME, Kern TS \& Schmidt AM 2009 Therapies for hyperglycaemia-induced diabetic complications: from animal models to clinical trials. Nature Reviews. Drug Discovery 8 417-429. (doi:10.1038/nrd2476)

Cao Y, Hao Y, Li H, Liu Q, Gao F, Liu W \& Duan H 2014 Role of endoplasmic reticulum stress in apoptosis of differentiated mouse podocytes induced by high glucose. International Journal of Molecular Medicine 33 809-816. (doi:10.3892/ijmm.2014.1642)

Chang CC, Chang CY, Wu YT, Huang JP, Yen TH \& Hung LM 2011 Resveratrol retards progression of diabetic nephropathy through modulations of oxidative stress, proinflammatory cytokines, and AMP-activated protein kinase. Journal of Biomedical Science 1847. (doi:10.1186/1423-0127-18-47)

Chen Y, Liu CP, Xu KF, Mao XD, Lu YB, Fang L, Yang JW \& Liu C 2008 Effect of taurine-conjugated ursodeoxycholic acid on endoplasmic reticulum stress and apoptosis induced by advanced glycation end products in cultured mouse podocytes. American Journal of Nephrology $\mathbf{2 8}$ 1014-1022. (doi:10.1159/000148209)

Choi AM, Ryter SW \& Levine B 2013 Autophagy in human health and disease. New England Journal of Medicine 368 651-662. (doi:10.1056/ NEJMra1205406) http://joe.endocrinology-journals.org DOI: 10.1530/JOE-14-0437 (c) 2015 Society for Endocrinology Printed in Great Britain 
Chuang PY, Dai Y, Liu R, He H, Kretzler M, Jim B, Cohen CD \& He JC 2011 Alteration of forkhead box $\mathrm{O}$ (foxo4) acetylation mediates apoptosis of podocytes in diabetes mellitus. PLoS ONE 6 e23566. (doi:10.1371/ journal.pone.0023566)

Ding DF, You N, Wu XM, Xu JR, Hu AP, Ye XL, Zhu Q, Jiang XQ, Miao H, Liu C et al. 2010a Resveratrol attenuates renal hypertrophy in earlystage diabetes by activating AMPK. American Journal of Nephrology 31 363-374. (doi:10.1159/000300388)

Ding Y, Kim JK, Kim SI, Na HJ, Jun SY, Lee SJ \& Choi ME $2010 b$ TGF- $\beta 1$ protects against mesangial cell apoptosis via induction of autophagy. Journal of Biological Chemistry 285 37909-37919. (doi:10.1074/jbc. M109.093724)

Ding Y, Kim SL, Lee SY, Koo JK, Wang Z \& Choi ME 2014 Autophagy regulates TGF- $\beta$ expression and suppresses kidney fibrosis induced by unilateral ureteral obstruction. Journal of the American Society of Nephrology [in press]. (doi:10.1681/ASN.2013101068)

Fang L, Zhou Y, Cao H, Wen P, Jiang L, He W, Dai C \& Yang J 2013 Autophagy attenuates diabetic glomerular damage through protection of hyperglycemia-induced podocyte injury. PLOS ONE 8 e60546. (doi:10.1371/journal.pone.0060546)

Fervenza FC, Fitzpatrick PM, Mertz J, Erickson SB, Liggett S, Popham S, Wochos DN, Synhavsky A, Hippler S, Larson TS et al. 2004 Acute rapamycin nephrotoxicity in native kidneys of patients with chronic glomerulopathies. Nephrology, Dialysis, Transplantation 19 1288-1292. (doi:10.1093/ndt/gfh079)

Fiorentino L, Cavalera M, Menini S, Marchetti V, Mavilio M, Fabrizi M, Conserva F, Casagrande V, Menghini R, Pontrelli P et al. 2013 Loss of TIMP3 underlies diabetic nephropathy via FoxO1/STAT1 interplay. EMBO Molecular Medicine 5 441-455. (doi:10.1002/emmm.201201475)

Forbes MS, Thornhill BA \& Chevalier RL 2011 Proximal tubular injury and rapid formation of atubular glomeruli in mice with unilateral ureteral obstruction: a new look at an old model. American Journal of Physiology. Renal Physiology 301 F110-F117. (doi:10.1152/ajprenal.00022.2011)

Friederich M, Fasching A, Hansell P, Nordquist L \& Palm F 2008 Diabetesinduced up-regulation of uncoupling protein-2 results in increased mitochondrial uncoupling in kidney proximal tubular cells. Biochimica et Biophysica Acta 1777 935-940. (doi:10.1016/j.bbabio.2008.03.030)

Giacco F \& Brownlee M 2010 Oxidative stress and diabetic complications. Circulation Research 107 1058-1070. (doi:10.1161/CIRCRESAHA.110. 223545)

Gödel M, Hartleben B, Herbach N, Liu S, Zschiedrich S, Lu S, DebreczeniMór A, Lindenmeyer MT, Rastaldi MP, Hartleben G et al. 2011 Role of mTOR in podocyte function and diabetic nephropathy in humans and mice. Journal of Clinical Investigation 121 2197-2209. (doi:10.1172/ JCI44774)

Hamasaki M, Furuta N, Matsuda A, Nezu A, Yamamoto A, Fujita N, Oomori H, Noda T, Haraguchi T, Hiraoka Y et al. 2013 Autophagosomes form at ER-mitochondria contact sites. Nature 495 389-393. (doi:10.1038/ nature11910)

Han K, Zhou H \& Pfeifer U 1997 Inhibition and restimulation by insulin of cellular autophagy in distal tubular cells of the kidney in early diabetic rats. Kidney \& Blood Pressure Research 20 258-263. (doi:10.1159/ 000174155)

Har R, Scholey JW, Daneman D, Mahmud FH, Dekker R, Lai V, Elia Y, Fritzler ML, Sochett EB, Reich HN et al. 2013 The effect of renal hyperfiltration on urinary inflammatory cytokines/chemokines in patients with uncomplicated type 1 diabetes mellitus. Diabetologia 56 1166-1173. (doi:10.1007/s00125-013-2857-5)

Hartleben B, Gödel M, Meyer-Schwesinger C, Liu S, Ulrich T, Köbler S, Wiech T, Grahammer F, Arnold SJ, Lindenmeyer MT et al. 2010 Autophagy influences glomerular disease susceptibility and maintains podocyte homeostasis in aging mice. Journal of Clinical Investigation 120 1084-1096. (doi:10.1172/JCI39492)

Hasegawa K, Wakino S, Simic P, Sakamaki Y, Minakuchi H, Fujimura K, Hosoya K, Komatsu M, Kaneko Y, Kanda T et al. 2013 Renal tubular Sirt1 attenuates diabetic albuminuria by epigenetically suppressing
Claudin-1 overexpression in podocytes. Nature Medicine 19 1496-1504. (doi:10.1038/nm.3363)

He C \& Levine B 2010 The Beclin 1 interactome. Current Opinion in Cell Biology 22 140-149. (doi:10.1016/j.ceb.2010.01.001)

He W, Wang Y, Zhang MZ, You L, Davis LS, Fan H, Yang HC, Fogo AB, Zent R, Harris RC et al. 2010 Sirt1 activation protects the mouse renal medulla from oxidative injury. Journal of Clinical Investigation 120 1056-1068. (doi:10.1172/JCI41563)

Hu FB 2011 Globalization of diabetes. Diabetes Care 34 1249-1257. (doi:10.2337/dc11-0442)

Hummasti S \& Hotamisligil GS 2010 Endoplasmic reticulum stress and inflammation in obesity and diabetes. Circulation Research $\mathbf{1 0 7}$ 579-591. (doi:10.1161/CIRCRESAHA.110.225698)

Ichihara A, Suzuki F, Nakagawa T, Kaneshiro Y, Takemitsu T, Sakoda M, Nabi AH, Nishiyama A, Sugaya T, Hayashi M et al. 2006 Prorenin receptor blockade inhibits development of glomerulosclerosis in diabetic angiotensin II type 1a receptor-deficient mice. Journal of the American Society of Nephrology 17 1950-1961. (doi:10.1681/ASN.2006010029)

Inoki K, Mori H, Wang J, Suzuki T, Hong S, Yoshida S, Blattner SM, Ikenoue T, Rüegg MA, Hall MN et al. 2011 mTORC1 activation in podocytes is a critical step in the development of diabetic nephropathy in mice. Journal of Clinical Investigation 121 2181-2196. (doi:10.1172/JCI44771)

Jiang M, Liu K, Luo J \& Dong Z 2010 Autophagy is a renoprotective mechanism during in vitro hypoxia and in vivo ischemia-reperfusion injury. American Journal of Pathology 176 1181-1192. (doi:10.2353/ ajpath.2010.090594)

Kanwar YS, Sun L, Xie P, Liu FY \& Chen S 2011 A glimpse of various pathogenetic mechanisms of diabetic nephropathy. Annual Review of Pathology 6 395-423. (doi:10.1146/annurev.pathol.4.110807.092150)

van Kats JP, Schalekamp MA, Verdouw PD, Duncker DJ \& Danser AH 2001 Intrarenal angiotensin II: interstitial and cellular levels and site of production. Kidney International 60 2311-2317. (doi:10.1046/ j.1523-1755.2001.00049.x)

Kim J, Kundu M, Viollet B \& Guan KL 2011 AMPK and mTOR regulate autophagy through direct phosphorylation of Ulk1. Nature Cell Biology 13 132-141. (doi:10.1038/ncb2152)

Kim SI, Na HJ, Ding Y, Wang Z, Lee SJ \& Choi ME 2012a Autophagy promotes intracellular degradation of type I collagen induced by transforming growth factor (TGF)- $\beta 1$. Journal of Biological Chemistry $\mathbf{2 8 7}$ 11677-11688. (doi:10.1074/jbc.M111.308460)

Kim WY, Nam SA, Song HC, Ko JS, Park SH, Kim HL, Choi EJ, Kim YS, Kim J \& Kim YK $2012 b$ The role of autophagy in unilateral ureteral obstruction rat model. Nephrology 17 148-159. (doi:10.1111/j.14401797.2011.01541.x)

Kim MY, Lim JH, Youn HH, Hong YA, Yang KS, Park HS, Chung S, Ko SH, Shin SJ, Choi BS et al. 2013 Resveratrol prevents renal lipotoxicity and inhibits mesangial cell glucotoxicity in a manner dependent on the AMPK-SIRT1-PGC1 $\alpha$ axis in db/db mice. Diabetologia 56 204-217. (doi:10.1007/s00125-012-2747-2)

Kimura T, Takabatake Y, Takahashi A, Kaimori JY, Matsui I, Namba T, Kitamura H, Niimura F, Matsusaka T, Soga T et al. 2011 Autophagy protects the proximal tubule from degeneration and acute ischemic injury. Journal of the American Society of Nephrology 22 902-913. (doi:10.1681/ASN.2010070705)

Kitada M, Takeda A, Nagai T, Ito H, Kanasaki K \& Koya D 2011a Dietary restriction ameliorates diabetic nephropathy through anti-inflammatory effects and regulation of the autophagy via restoration of Sirt1 in diabetic Wistar fatty (fa/fa) rats: a model of type 2 diabetes. Experimental Diabetes Research 2011 908185. (doi:10.1155/2011/908185)

Kitada M, Kume S, Imaizumi N \& Koya D $2011 b$ Resveratrol improves oxidative stress and protects against diabetic nephropathy through normalization of Mn-SOD dysfunction in AMPK/SIRT1-independent pathway. Diabetes $60634-643$. (doi:10.2337/db10-0386)

Koesters R, Kaissling B, Lehir M, Picard N, Theilig F, Gebhardt R, Glick AB, Hähnel B, Hosser H, Gröne HJ et al. 2010 Tubular overexpression of transforming growth factor- $\beta 1$ induces autophagy and fibrosis but not 
mesenchymal transition of renal epithelial cells. American Journal of Pathology 177 632-643. (doi:10.2353/ajpath.2010.091012)

Koya D, Hayashi K, Kitada M, Kashiwagi A, Kikkawa R \& Haneda M 2003 Effects of antioxidants in diabetes-induced oxidative stress in the glomeruli of diabetic rats. Journal of the American Society of Nephrology $\mathbf{1 4}$ S250-S253. (doi:10.1097/01.ASN.0000077412.07578.44)

Kroemer G, Mariño G \& Levine B 2010 Autophagy and the integrated stress response. Molecular Cell 40 280-293. (doi:10.1016/j.molcel.2010.09.023)

Kume S, Uzu T, Horiike K, Chin-Kanasaki M, Isshiki K, Araki S, Sugimoto T, Haneda M, Kashiwagi A \& Koya D 2010 Calorie restriction enhances cell adaptation to hypoxia through Sirt1-dependent mitochondrial autophagy in mouse aged kidney. Journal of Clinical Investigation 120 1043-1055. (doi:10.1172/JCI41376)

Lee MJ, Feliers D, Mariappan MM, Sataranatarajan K, Mahimainathan L, Musi N, Foretz M, Viollet B, Weinberg JM, Choudhury GG et al. 2007 A role for AMP-activated protein kinase in diabetes-induced renal hypertrophy. American Journal of Physiology. Renal Physiology 292 F617-F627. (doi:10.1152/ajprenal.00278.2006)

Lee IH, Cao L, Mostoslavsky R, Lombard DB, Liu J, Bruns NE, Tsokos M, Alt FW \& Finkel T 2008 A role for the NAD-dependent deacetylase Sirt1 in the regulation of autophagy. PNAS 105 3374-3379. (doi:10.1073/pnas.0712145105)

Lee JW, Park S, Takahashi Y \& Wang HG 2010 The association of AMPK with ULK1 regulates autophagy. PLoS ONE 5 e15394. (doi:10.1371/ journal.pone.0015394)

Lewis EJ, Hunsicker LG, Clarke WR, Berl T, Pohl MA, Lewis JB, Ritz E, Atkins RC, Rohde R, Raz I et al. 2001 Renoprotective effect of the angiotensin-receptor antagonist irbesartan in patients with nephropathy due to type 2 diabetes. New England Journal of Medicine $\mathbf{3 4 5}$ 851-860. (doi:10.1056/NEJMoa011303)

Li C, Cai F, Yang Y, Zhao X, Wang C, Li J, Jia Y, Tang J \& Liu Q $2010 a$ Tetrahydroxystilbene glucoside ameliorates diabetic nephropathy in rats: involvement of SIRT1 and TGF- $\beta 1$ pathway. European Journal of Pharmacology 649 382-389. (doi:10.1016/j.ejphar.2010.09.004)

Li L, Zepeda-Orozco D, Black R \& Lin F $2010 b$ Autophagy is a component of epithelial cell fate in obstructive uropathy. American Journal of Pathology 176 1767-1778. (doi:10.2353/ajpath.2010.090345)

Lieberthal W \& Levine JS 2009 The role of the mammalian target of rapamycin (mTOR) in renal disease. Journal of the American Society of Nephrology 20 2493-2502. (doi:10.1681/ASN.2008111186)

Lindenmeyer MT, Rastaldi MP, Ikehata M, Neusser MA, Kretzler M, Cohen CD \& Schlöndorff D 2008 Proteinuria and hyperglycemia induce endoplasmic reticulum stress. Journal of the American Society of Nephrology 19 2225-2236. (doi:10.1681/ASN.2007121313)

Liu S, Hartleben B, Kretz O, Wiech T, Igarashi P, Mizushima N, Walz G \& Huber TB 2012 Autophagy plays a critical role in kidney tubule maintenance, aging and ischemia-reperfusion injury. Autophagy $\mathbf{8}$ 826-837. (doi:10.4161/auto.19419)

Lloberas N, Cruzado JM, Franquesa M, Herrero-Fresneda I, Torras J, Alperovich G, Rama I, Vidal A \& Grinyó JM 2006 Mammalian target of rapamycin pathway blockade slows progression of diabetic kidney disease in rats. Journal of the American Society of Nephrology $\mathbf{1 7}$ 1395-1404. (doi:10.1681/ASN.2005050549)

Lu X, Roksnoer LC \& Danser AH 2013 The intrarenal renin-angiotensin system: does it exist? Implications from a recent study in renal angiotensin-converting enzyme knockout mice Nephrology, Dialysis, Transplantation 28 2977-2982. (doi:10.1093/ndt/gft333)

Ma T, Zhu J, Chen X, Zha D, Singhal PC \& Ding G 2013 High glucose induces autophagy in podocytes. Experimental Cell Research 319 779-789. (doi:10.1016/j.yexcr.2013.01.018)

Mijaljica D, Prescott M \& Devenish RJ 2011 Microautophagy in mammalian cells: revisiting a 40-year-old conundrum. Autophagy 7 673-682. (doi:10.4161/auto.7.7.14733)

Mori H, Inoki K, Masutani K, Wakabayashi Y, Komai K, Nakagawa R, Guan KL \& Yoshimura A 2009 The mTOR pathway is highly activated in diabetic nephropathy and rapamycin has a strong therapeutic potential. Biochemical and Biophysical Research Communications 384 471-475. (doi:10.1016/j.bbrc.2009.04.136)

Mortimore GE \& Pösö AR 1987 Intracellular protein catabolism and its control during nutrient deprivation and supply. Annual Review of Nutrition 7 539-564. (doi:10.1146/annurev.nu.07.070187.002543)

Moynihan KA, Grimm AA, Plueger MM, Bernal-Mizrachi E, Ford E, CrasMéneur C, Permutt MA \& Imai S 2005 Increased dosage of mammalian Sir2 in pancreatic $\beta$ cells enhances glucose-stimulated insulin secretion in mice. Cell Metabolism 2 105-117. (doi:10.1016/j.cmet.2005.07.001)

Muller DN, Klanke B, Feldt S, Cordasic N, Hartner A, Schmieder RE, Luft FC \& Hilgers KF 2008 (Pro)renin receptor peptide inhibitor "handleregion" peptide does not affect hypertensive nephrosclerosis in Goldblatt rats. Hypertension 51 676-681. (doi:10.1161/HYPERTENSIONAHA.107.101493)

Nair S \& Wilding JP 2010 Sodium glucose cotransporter 2 inhibitors as a new treatment for diabetes mellitus. Journal of Clinical Endocrinology and Metabolism 95 34-42. (doi:10.1210/jc.2009-0473)

Nakagawa T, Tanabe K, Croker BP, Johnson RJ, Grant MB, Kosugi T \& Li Q 2011 Endothelial dysfunction as a potential contributor in diabetic nephropathy. Nature Reviews. Nephrology 7 36-44. (doi:10.1038/ nrneph.2010.152)

Nguyen G \& Muller DN 2010 The biology of the (pro)renin receptor. Journal of the American Society of Nephrology 21 18-23. (doi:10.1681/ASN. 2009030300)

Nishikawa T, Edelstein D, Du XL, Yamagishi S, Matsumura T, Kaneda Y, Yorek MA, Beebe D, Oates PJ, Hammes HP et al. 2000 Normalizing mitochondrial superoxide production blocks three pathways of hyperglycaemic damage. Nature $\mathbf{4 0 4}$ 787-790. (doi:10.1038/35008121)

Noh H \& King GL 2007 The role of protein kinase C activation in diabetic nephropathy. Kidney International. Supplement 106 S49-S53. (doi:10.1038/sj.ki.5002386)

Ohse T, Inagi R, Tanaka T, Ota T, Miyata T, Kojima I, Ingelfinger JR, Ogawa S, Fujita T \& Nangaku M 2006 Albumin induces endoplasmic reticulum stress and apoptosis in renal proximal tubular cells. Kidney International 70 1447-1455. (doi:10.1038/sj.ki.5001704)

Oshima Y, Kinouchi K, Ichihara A, Sakoda M, Kurauchi-Mito A, Bokuda K, Narita T, Kurosawa H, Sun-Wada GH, Wada Y et al. 2011 Prorenin receptor is essential for normal podocyte structure and function. Journal of the American Society of Nephrology 22 2203-2212. (doi:10.1681/ ASN.2011020202)

Peng KY, Horng LY, Sung HC, Huang HC \& Wu RT 2011 Hepatocyte growth factor has a role in the amelioration of diabetic vascular complications via autophagic clearance of advanced glycation end products: Dispo85E, an HGF inducer, as a potential botanical drug. Metabolism 60 888-892. (doi:10.1016/j.metabol.2010.08.009)

Price NL, Gomes AP, Ling AJ, Duarte FV, Martin-Montalvo A, North BJ, Agarwal B, Ye L, Ramadori G, Teodoro JS et al. 2012 SIRT1 is required for AMPK activation and the beneficial effects of resveratrol on mitochondrial function. Cell Metabolism 15 675-690. (doi:10.1016/j.cmet.2012.04.003)

Qi W, Mu J, Luo ZF, Zeng W, Guo YH, Pang Q, Ye ZL, Liu L, Yuan FH \& Feng B 2011 Attenuation of diabetic nephropathy in diabetes rats induced by streptozotocin by regulating the endoplasmic reticulum stress inflammatory response. Metabolism 60 594-603. (doi:10.1016/j.metabol. 2010.07.021)

Ravikumar B, Sarkar S, Davies JE, Futter M, Garcia-Arencibia M, GreenThompson ZW, Jimenez-Sanchez M, Korolchuk VI, Lichtenberg M, Luo $\mathrm{S}$ et al. 2010 Regulation of mammalian autophagy in physiology and pathophysiology. Physiological Reviews 90 1383-1435. (doi:10.1152/physrev.00030.2009)

Riediger F, Quack I, Qadri F, Hartleben B, Park JK, Potthoff SA, Sohn D, Sihn G, Rousselle A, Fokuhl V et al. 2011 Prorenin receptor is essential for podocyte autophagy and survival. Journal of the American Society of Nephrology 22 2193-2202. (doi:10.1681/ASN.2011020200)

Rouschop KM, van den Beucken T, Dubois L, Niessen H, Bussink J, Savelkouls K, Keulers T, Mujcic H, Landuyt W, Voncken JW et al. 2010 The unfolded protein response protects human tumor cells during 
hypoxia through regulation of the autophagy genes MAP1LC3B and ATG5. Journal of Clinical Investigation 120 127-141. (doi:10.1172/ JCI40027)

Ruggenenti P, Cravedi P \& Remuzzi G 2010 The RAAS in the pathogenesis and treatment of diabetic nephropathy. Nature Reviews. Nephrology 6 319-330. (doi:10.1038/nrneph.2010.58)

Sakaguchi M, Isono M, Isshiki K, Sugimoto T, Koya D \& Kashiwagi A 2006 Inhibition of mTOR signaling with rapamycin attenuates renal hypertrophy in the early diabetic mice. Biochemical and Biophysical Research Communications 340 296-301. (doi:10.1016/j.bbrc.2005.12.012)

Sataranatarajan K, Mariappan MM, Lee MJ, Feliers D, Choudhury GG, Barnes JL \& Kasinath BS 2007 Regulation of elongation phase of mRNA translation in diabetic nephropathy: amelioration by rapamycin. American Journal of Pathology 171 1733-1742. (doi:10.2353/ajpath. 2007.070412)

Satofuka S, Ichihara A, Nagai N, Noda K, Ozawa Y, Fukamizu A, Tsubota K, Itoh H, Oike Y \& Ishida S 2009 (Pro)renin receptor-mediated signal transduction and tissue renin-angiotensin system contribute to diabetes-induced retinal inflammation. Diabetes 58 1625-1633. (doi:10.2337/db08-0254)

Shi Y \& Hu FB 2014 The global implications of diabetes and cancer. Lancet 383 1947-1948. (doi:10.1016/S0140-6736(14)60886-2)

Sieber J, Lindenmeyer MT, Kampe K, Campbell KN, Cohen CD, Hopfer H, Mundel P \& Jehle AW 2010 Regulation of podocyte survival and endoplasmic reticulum stress by fatty acids. American Journal of Physiology. Renal Physiology 299 F821-F829. (doi:10.1152/ajprenal. 00196.2010)

Sokolovska J, Isajevs S, Sugoka O, Sharipova J, Lauberte L, Svirina D, Rostoka E, Sjakste T, Kalvinsh I \& Sjakste N 2010 Influence of metformin on GLUT1 gene and protein expression in rat streptozotocin diabetes mellitus model. Archives of Physiology and Biochemistry 116 137-145. (doi:10.3109/13813455.2010.494672)

Sooparb S, Price SR, Shaoguang J \& Franch HA 2004 Suppression of chaperone-mediated autophagy in the renal cortex during acute diabetes mellitus. Kidney International 65 2135-2144. (doi:10.1111/j. 1523-1755.2004.00639.x)

Stehouwer CD 2004 Endothelial dysfunction in diabetic nephropathy: state of the art and potential significance for non-diabetic renal disease. Nephrology, Dialysis, Transplantation 19 778-781. (doi:10.1093/ndt/gfh015)

Sun C, Zhang F, Ge X, Yan T, Chen X, Shi X \& Zhai Q 2007 SIRT1 improves insulin sensitivity under insulin-resistant conditions by repressing PTP1B. Cell Metabolism 6 307-319. (doi:10.1016/j.cmet.2007.08.014)

Takahashi H, Ichihara A, Kaneshiro Y, Inomata K, Sakoda M, Takemitsu T, Nishiyama A \& Itoh H 2007 Regression of nephropathy developed in diabetes by (pro)renin receptor blockade. Journal of the American Society of Nephrology 18 2054-2061. (doi:10.1681/ASN.2006080820)

Tan AL, Forbes JM \& Cooper ME 2007 AGE, RAGE, and ROS in diabetic nephropathy. Seminars in Nephrology 27 130-143. (doi:10.1016/j. semnephrol.2007.01.006)

Tikoo K, Tripathi DN, Kabra DG, Sharma V \& Gaikwad AB 2007 Intermittent fasting prevents the progression of type I diabetic nephropathy in rats and changes the expression of Sir2 and p53. FEBS Letters 581 1071-1078. (doi:10.1016/i.febslet.2007.02.006)

Turan B, Tuncay E \& Vassort G 2012 Resveratrol and diabetic cardiac function: focus on recent in vitro and in vivo studies. Journal of Bioenergetics and Biomembranes 44 281-296. (doi:10.1007/s10863-012-9429-0)

Vallon V, Rose M, Gerasimova M, Satriano J, Platt KA, Koepsell H, Cunard R, Sharma K, Thomson SC \& Rieg T 2013 Knockout of Na-glucose transporter SGLT2 attenuates hyperglycemia and glomerular hyperfiltration but not kidney growth or injury in diabetes mellitus.
American Journal of Physiology. Renal Physiology 304 F156-F167. (doi:10. 1152/ajprenal.00409.2012)

Walter P \& Ron D 2011 The unfolded protein response: from stress pathway to homeostatic regulation. Science 334 1081-1086. (doi:10.1126/ science.1209038)

Wang Z \& Choi ME 2014 Autophagy in kidney health and disease. Antioxidants \& Redox Signaling 20 519-537. (doi:10.1089/ars.2013.5363)

Wittmann S, Daniel C, Stief A, Vogelbacher R, Amann K \& Hugo C 2009 Long-term treatment of sirolimus but not cyclosporine ameliorates diabetic nephropathy in the rat. Transplantation 87 1290-1299. (doi:10.1097/TP.0b013e3181a192bd)

Wolf G, Chen S \& Ziyadeh FN 2005 From the periphery of the glomerular capillary wall toward the center of disease: podocyte injury comes of age in diabetic nephropathy. Diabetes 54 1626-1634. (doi:10.2337/ diabetes.54.6.1626)

Wu L, Zhang Y, Ma X, Zhang N \& Qin G 2012 The effect of resveratrol on FoxO1 expression in kidneys of diabetic nephropathy rats. Molecular Biology Reports 39 9085-9093. (doi:10.1007/s11033-012-1780-z)

Xavier S, Gilbert V, Rastaldi MP, Krick S, Kollins D, Reddy A, Bottinger E, Cohen CD \& Schlondorff D 2010 BAMBI is expressed in endothelial cells and is regulated by lysosomal/autolysosomal degradation. PLoS ONE 5 e12995. (doi:10.1371/journal.pone.0012995)

Xu Y, Nie L, Yin YG, Tang JL, Zhou JY, Li DD \& Zhou SW 2012 Resveratrol protects against hyperglycemia-induced oxidative damage to mitochondria by activating SIRT1 in rat mesangial cells. Toxicology and Applied Pharmacology 259 395-401. (doi:10.1016/j.taap.2011.09.028)

Xu Y, Ruan S, Wu X, Chen H, Zheng K \& Fu B 2013 Autophagy and apoptosis in tubular cells following unilateral ureteral obstruction are associated with mitochondrial oxidative stress. International Journal of Molecular Medicine 31 628-636. (doi:10.3892/ijmm.2013.1232)

Yadav A, Vallabu S, Arora S, Tandon P, Slahan D, Teichberg S \& Singhal PC 2010 ANG II promotes autophagy in podocytes. American Journal of Physiology. Cell Physiology 299 C488-C496. (doi:10.1152/ajpcell. 00424.2009)

Yamahara K, Kume S, Koya D, Tanaka Y, Morita Y, Chin-Kanasaki M, Araki H, Isshiki K, Araki S, Haneda M et al. 2013 Obesity-mediated autophagy insufficiency exacerbates proteinuria-induced tubulointerstitial lesions. Journal of the American Society of Nephrology $\mathbf{2 4}$ 1769-1781. (doi:10.1681/ASN.2012111080)

Yang Y, Wang J, Qin L, Shou Z, Zhao J, Wang H, Chen Y \& Chen J 2007 Rapamycin prevents early steps of the development of diabetic nephropathy in rats. American Journal of Nephrology 27 495-502. (doi:10.1159/000106782)

Zhang J 2007 The direct involvement of SirT1 in insulin-induced insulin receptor substrate-2 tyrosine phosphorylation. Journal of Biological Chemistry 282 34356-34364. (doi:10.1074/jbc.M706644200)

Zhang S, Cai G, Fu B, Feng Z, Ding R, Bai X, Liu W, Zhuo L, Sun L, Liu F et al. 2012 SIRT1 is required for the effects of rapamycin on high glucoseinducing mesangial cells senescence. Mechanisms of Ageing and Development 133 387-400. (doi:10.1016/j.mad.2012.04.005)

Zhang MZ, Wang Y, Paueksakon P \& Harris RC 2014 Epidermal growth factor receptor inhibition slows progression of diabetic nephropathy in association with a decrease in endoplasmic reticulum stress and an increase in autophagy. Diabetes 63 2063-2072. (doi:10.2337/db13-1279)

Zhong Y, Wang QJ, Li X, Yan Y, Backer JM, Chait BT, Heintz N \& Yue Z 2009 Distinct regulation of autophagic activity by Atg14L and Rubicon associated with Beclin 1-phosphatidylinositol-3-kinase complex. Nature Cell Biology 11 468-476. (doi:10.1038/ncb1854)

Zoncu R, Efeyan A \& Sabatini DM 2011 mTOR: from growth signal integration to cancer, diabetes and ageing. Nature Reviews. Molecular Cell Biology 12 21-35. (doi:10.1038/nrm3025)

Received in final form 21 October 2014

Accepted 27 October 2014

Accepted Preprint published online 27 October 2014 http://joe.endocrinology-journals.org DOI: 10.1530/JOE-14-0437
() 2015 Society for Endocrinology Printed in Great Britain 